\title{
Prevalence of gram negative bacteria causing community acquired pneumonia among adults in Mwanza City, Tanzania
}

\author{
Peter Kishimbo ${ }^{1}$, Nyambura Moremi Sogone ${ }^{2}$, Fredrick Kalokola ${ }^{1}$ and Stephen E. Mshana ${ }^{3^{*}}$
}

\begin{abstract}
Background: Community acquired pneumonia (CAP) in adults is still a common and serious illness in the sub-Saharan Africa. Identification of the pathogens is crucial in the management of CAP. This study was done to determine the common bacterial pathogens, treatment outcomes and associated factors for microbiological confirmed CAP among adults attending the Bugando Medical Centre and Sekou Toure hospital in the city of Mwanza, Tanzania.

Methods: This was a hospital based cross sectional study involving patients with community acquired pneumonia attending Bugando Medical Centre and Sekou Toure regional Hospital. Demographic and other data were collected using standardized data collection tool. Sputum culture was done followed by identification of the isolates and antibiotics susceptibility testing.
\end{abstract}

Results: A total of 353 patients were enrolled in the study. Out of 353 sputum samples, 265(75\%) were of good quality. Of 353 non-repetitive sputum cultures, $72 / 353(20.4,95 \% \mathrm{Cl}$ : 16.2-24.6) were positive for the bacterial pathogens with five patients having more than one pathogen. Good quality sputa had significantly higher yield of pathogenic bacteria than poor quality sputa $(26.1 \%$ vs.3.4\%, $P=0.001)$. The majority $64(83.1 \%)$ of the isolates were gram negative bacteria. Common bacteria isolated were Klebsiella pneumoniae 23/77(29.9\%), Streptococcus pyogenes 10/77 (13.0\%), Pseudomonas aeruginosa 9/77 (11.7\%) and Escherichia coli 7/77 (9.1\%). Of 23 K. pneumoniae isolates, 20/23 (87.0\%) were resistant to ceftriaxone. Resistance to ceftriaxone was found to be associated with prolongation of CAP symptoms $(p=0.009)$.

Conclusion: Gram negative bacteria resistant to ampicillin, amoxicillin/clavulanic acid and ceftriaxone were most frequently isolated bacteria among adults' patients with CAP attending BMC and Sekou Toure hospital. Routine sputum culture should be performed to guide appropriate treatment of CAP among adults in developing countries.

\section{Background}

Community-acquired pneumonia (CAP) according to British Thoracic Society is defined as an acute symptomatic infection of the pulmonary parenchyma which develops outside the hospital or nursing home as evidenced by a new infiltrate demonstrated on chest radiograph or auscultatory findings consistent with

\footnotetext{
* Correspondence: stephen72mshana@gmail.com

${ }^{3}$ Department of Microbiology//mmunology, Weill Bugando School of Medicine, Mwanza, Tanzania

Full list of author information is available at the end of the article
}

pneumonia [1]. CAP is increasing in the sub-Saharan Africa and is among the major cause of morbidity and mortality among adults [2-4]. CAP ranks third as the most common cause of death worldwide [5, 6]. CAP is prevalent in both developing and developed countries; however it is about five times more common in developing countries [6, 7].

Etiological causes of CAP vary significantly between countries [7], also there are variations within the same countries [8]. Etiological variations are due to irrational use of antibiotics, environmental pollution, advancement

(c) The Author(s). 2020 Open Access This article is licensed under a Creative Commons Attribution 4.0 International License, which permits use, sharing, adaptation, distribution and reproduction in any medium or format, as long as you give appropriate credit to the original author(s) and the source, provide a link to the Creative Commons licence, and indicate if changes were made. The images or other third party material in this article are included in the article's Creative Commons licence, unless indicated otherwise in a credit line to the material. If material is not included in the article's Creative Commons licence and your intended use is not permitted by statutory regulation or exceeds the permitted use, you will need to obtain permission directly from the copyright holder. To view a copy of this licence, visit http://creativecommons.org/licenses/by/4.0/. 
in diagnostic techniques/tools and increased awareness of the disease [9]. Diagnosis of CAP depends on different diagnostics methods; including chest radiography which is required to demonstrate new infiltrates, sputum and blood culture which can confirm the microbiological pathogens [8]. Microbiological studies of sputum (microscopic examination of sputum specimens and sputum culture) can yield the correct diagnosis of CAP in the majority of cases [8]. Different guidelines including those from Infectious Disease Society of America (IDSA) recommend 2 pre-treatment blood cultures as well as gram staining and culture of the sputum in the diagnosis of CAP [8].

Studies in Europe, United Sates and Asia have documented Streptococcus pneumoniae as the most isolated organism responsible for the CAP [10]. In the developing countries, despite CAP being the commonest reason for hospital visits, there are limited information regarding the etiological causes of CAP in these countries [11].

No prior study has been done at the Bugando Medical Centre (BMC) and Sekou Toure hospital to document the pathogens causing CAP. The current empirical treatment depends on the data from developed countries which might not be applicable in our setting. In the view of this burden and the increasing concern about irrational use of antibiotics, this study aimed at determining the etiological pathogens and susceptibility patterns of isolates causing community acquired pneumonia among adults attending Bugando and Sekou Toure hospital in Mwanza City, Tanzania.

\section{Methods}

\section{Study design and site}

This was a hospital based cross sectional study conducted in medical wards and medical outpatient departments of the Bugando Medical Centre (BMC) and Sekou Toure regional hospital between August 2015 and December 2015. The study included in-patients and outpatients' adults aged 18 years and above who met inclusion criteria.

\section{Sample size calculation}

The Kish Leslie [12] formula was used to calculate the required sample size using proportion from a study in Kenya which observed $65 \%$ of patients with CAP had defined etiology [13] giving a minimum sample size of 350 adult patients.

\section{Inclusion criteria and exclusion criteria}

Out- and in-patients adult aged 18 years or above attending at BMC and Sekou Toure regional hospital with productive cough and at least 2 symptoms of acute lower respiratory infections were included. These symptoms included: change in color of respiratory secretions in a patient with chronic cough, axillary temperature of $>37.5^{\circ} \mathrm{C}$ or hypothermia $36.1^{\circ} \mathrm{C}$, chest discomfort or the onset of dyspnea, new chest clinical features (rales, wheezing, absence of breath sounds, egophony etc.) consistent with pneumonia demonstrated on auscultatory findings. The study excluded patients hospitalized for more than $48 \mathrm{~h}$ prior to enrollment in the study, patients who were discharged from the hospital within 2 weeks prior to study enrollment and those with cough of more than 2 weeks (Fig. 1).

\section{Data collection}

Data were collected using standardized data collection tool. Physical examination included a single blood pressure measurement which was obtained with automated blood pressure, deluxe automatic blood pressure monitor (HoMedics Inc., China). Other examinations were respiratory rate and pulse rate, measured as previously described [14]. Oxygen saturation was recorded in percentage by pulse oximeter (Beijing Choice Electronic Tech. Co. Ltd) placed on finger for at least $5 \mathrm{~min}$. All patients with no HIV results, were counseled for HIV testing following Tanzania HIV testing National algorithm [15].

All enrolled patients were provided with containers for sputum collection. Education was provided on how to collect quality sputum as described in Koneman's Color Atlas and Textbook of Diagnostic Microbiology [16].

All patients were followed for 14 days through telephone to determine the cure rate (disappearance of symptoms). Patients were treated by the discretion of doctor, but antibiotics were switched basing on culture and susceptibility results.

\section{Sputum processing}

Sputum specimens were processed according to BMC microbiology standard operation procedures. A BMC laboratory is accredited by the Southern African Development Community Accreditation Service (SADCAS) with a unique number MED 002. Specimens were examined both macroscopically and microscopically. Macroscopic appearance of the specimens were recorded i.e. saliva, purulent or bloodstained. Purulent portion of specimen was selected for microscopy studies and culture $[17,18]$. The quality of sputa was assessed using Bartlett et al., criteria. The sputum with Q-score of more than 1 , i.e. WBC more than 10 was considered acceptable and termed as good quality while a score of " 0 " or "- "was considered nonacceptable and termed as poor quality [19].

\section{Culture and identification}

The purulent part of the sputum was inoculated on Chocolate agar plate, Blood agar plate and MacConkey 


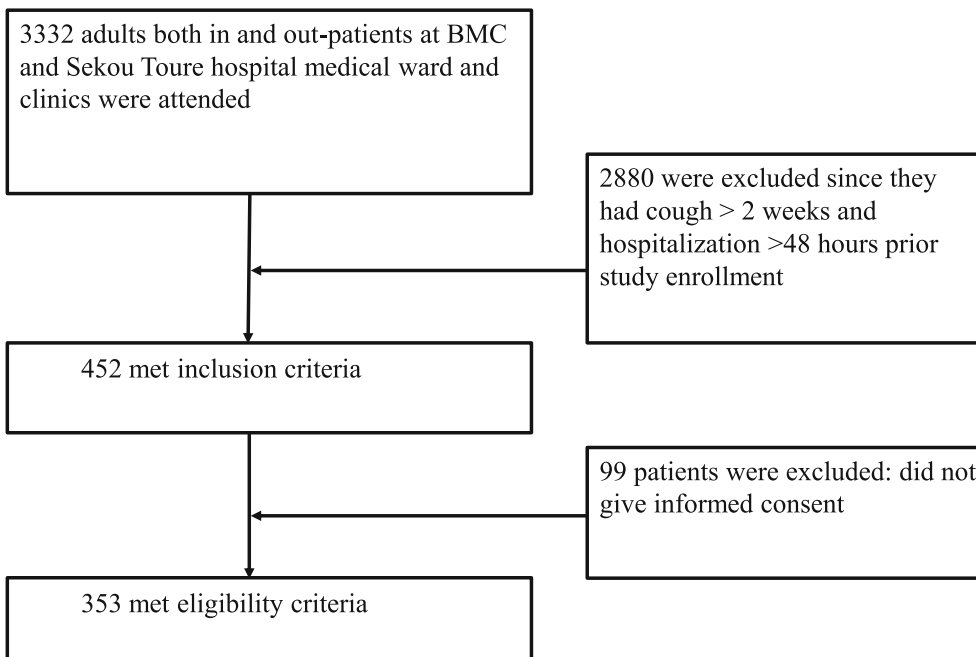

Fig. 1 Flow chart regarding patient recruitment

Agar (OXOID, Hampshire, United Kingdom) and incubated in $5-10 \% \mathrm{CO}_{2}$ for $24 \mathrm{~h}$. Cultures were read after $24 \mathrm{~h}$ and in some cases after $48 \mathrm{~h}$. Interpretations were recorded as semi-quantitative growth of all colonies (i.e. $+/-$ to ++++$)$. The significant growth of possible pathogens other than normal oral flora was considered as positive culture [20]. Pathogens were identified using in house biochemical and physiological properties as described previously $[17,21]$. All pathogens were subjected to the susceptibility testing using disc diffusion methods as per Clinical and Laboratory Standard Institute [22]. $S$. aureus isolates with cefoxitin $(30 \mu \mathrm{g})$ zone of inhibition of $\leq 21 \mathrm{~mm}$ were phenotypically considered as methicillin resistant Staphylococcus aureus (MRSA).

Streptococcus pneumoniae (ATCC 49619), Haemophilus influenzae (ATCC 49247/49766) and Staphylococcus aureus (ATCC 25923) were used as quality control strains.

\section{Data analysis}

Data were entered into computer using Microsoft Excel. Data cleaning was done by EpiData version 3.1 (CDC, Atlanta, USA) according to codes given and finally analyzed using STATA version 13 (College Station, Texas, USA). Binary and categorical variables (age, sex, blood pressure, oxygen saturation and respiratory rate monitoring) were described as proportions and percentages and compared using Chi-Square and Fisher's exact tests. Continuous variables were described as medians with interquartile ranges (IQR) and compared using Wilcoxon Rank Sum test. The primary outcome of this study was the culture positive for pathogens from expectorated sputum. The strength of association of the factors associated was determined using univariate logistic regression analysis to obtain odd ratio and its $95 \% \mathrm{CI}$. All variables with $\mathrm{p}$-value of less than 0.05 at $95 \%$ confidence interval were considered to have statistical significant difference.

\section{Results}

Demographic and other characteristics of the study population

A total of 353 adults were included in the study (Fig. 1). The median age was 40 (IQR; $32-52$ ) years. A total of 181 (51.3\%) participants were males. The majority of patients $322(91.2 \%)$ were enrolled in the medical outpatient clinics. Ninety three $(26.3 \%)$ of the patients had ever smoked tobacco containing products in their life. Diabetes Mellitus, heart diseases, chronic kidney disease and chronic obstructive pulmonary diseases (COPD) were reported in $40(11.3 \%)$ of the enrolled patients. One hundred-twenty two (34.6\%) of patients had history of antibiotics use in the past 7 days prior to the enrolment. None of the patients had ever been vaccinated for respiratory infections (Table 1).

\section{Bacterial pathogens and their susceptibility patterns}

Out of 353 non-repetitive sputum cultures, 72/353 (20.4, 95\% CI) were positive for bacterial pathogens with $5(1.4 \%)$ patients (Table 2) having more than one isolate. The majority of the isolates were gram negative bacteria 64 (83.1\%), Fig. 2. Out of 353 non-repetitive sputum samples, $265(75.1 \%)$ were of good quality. Common bacteria isolated were Klebsiella pneumoniae 23/ 77(29.9\%), Streptococcus pyogenes 10/77 (13.0\%), Pseudomonas aeruginosa 9/77 (11.7\%), Escherichia coli 7/77 (9.1\%), Haemophilus influenzae/parainfluenzae 3/77 (3.9\%), Staphylococcus aureus 2/77 (2.6\%) and Streptococcus pneumoniae 1/77 (1.3\%). Other bacteria isolated were: Citrobacter freundii (3/22), Enterobacter aerogenes (3/22), Klebsiella oxytoca (1/22), Moraxella spp.(1/22), 
Table 1 Baseline characteristics of 353 adult patients with pneumonia between August and December 2015 in Mwanza, Tanzania

\begin{tabular}{ll}
\hline Characteristics & Number (\%) \\
\hline Sex & $181(51.3)$ \\
Male & $172(48.7)$ \\
Female & $40(32-52)$ \\
Age (years) & \\
Hospitalization & $31(8.8)$ \\
$\quad$ Inpatients (Less than 48 h.) & $322(91.2)$ \\
Outpatients & \\
Level of formal education & $51(14.5)$ \\
$\quad$ None & $228(64.6)$ \\
Primary school & $64(18.1)$ \\
Secondary school & $10(2.8)$ \\
University/College &
\end{tabular}

Ever Smoked tobacco products

$\begin{array}{ll}\text { No } & 260(73.7) \\ \text { Yes } & 93(26.3)\end{array}$

Taking of alcohol-containing beverage

$\begin{array}{ll}\text { No } & 189(53.5) \\ \text { Yes } & 164(46.5)\end{array}$

HIV status

Negative $217(61.5)$

Positive 136 (38.5)

\section{Co-morbidities}

No $313(88.7)$

Yes $\quad 40$ (11.3)

Antibiotics use in the past 7 days

$\begin{array}{ll}\text { No } & 231(65.4) \\ \text { Yes } & 122(34.6)\end{array}$

Treatment

First line $\quad 265(75.1 \%)$

Second line $\quad 88$ (24.9\%)

In this study: First line antibiotics included Amoxicillin/clavulanic acid or Ampicillin and trimethoprim/ sulphamethoxazole, Second line antibiotics was either Ceftriaxone or Ceftazidime
Proteus mirabilis (2/22), Serratia marcescens $(1 / 22)$ and unidentified Gram Negative Rods (GNR) (11/22), Fig. 2.

Of 23 Klebsiella pneumoniae isolates, 21(91.3\%) were resistant to amoxicillin-clavulanic acid and 20 (87.0\%) were resistant to ceftriaxone. Escherichia coli isolates were $100 \%$ resistant to ampicillin with $6 / 7$ (85.7\%) being resistant to ceftriaxone (Table 3). All Staphylococcus aureus isolates were susceptible to trimethoprimsulfamethoxazole and none was phenotypically confirmed to be MRSA.

\section{Factors associated with sputum culture positive}

Out of 181 males, 41 (22.7\%) were found to be sputum culture positive compared to $31 / 172$ (18.0\%) females (OR 0.8, 95\%-CI, $(0.4-1.3, p=0.282)$. Those with history of antibiotics use in the past 7 days prior to enrollment, had low yield of sputum culture results compared to patients without prior antibiotics use $(18.2 \%$ versus $24.6 \%$, OR 1.5, 95\% CI:0.9-2.5, $p=0.157)$. Sputum samples of good quality had ten folds increased chances of yielding positive sputum cultures as compared to poor quality sputum (OR 10.1, 95\%CI;3.1-33.1, $P=<0.001$ ) (Table 4).

\section{Factors associated with uncommon pathogens}

A total of 39(54.2\%) of patients were infected by common pathogens (K. pneumoniae, S. pyogenes, $H$. influenza, $S$ aureus, S. pneumoniae, Moraxella spp.) while 33(45.8\%) were infected with uncommon pathogens (Pseudomonas spp., E. coli, Citrobacter spp., Enterobacter spp., Proteus spp., Serratia spp., and un-identified GNB). Out of 33 patients with uncommon pathogens, $12(36.4 \%)$ were HIV positive compared to $14 / 39(35.9 \%)$ who were HIV positive among those with common pathogens $(P=0.967)$. The sub-analysis between pathogens and antibiotic use in the past 7 days, revealed that, those with history of antibiotics use had higher positive culture due to uncommon pathogens than those who had no history of antibiotic use (18/30(60\%) vs. $15 / 42(35.7 \%), p=$ 0.041). Regarding co-morbidities, no significant different was observed in distribution of pathogens among those with comorbidities and those with no co-morbidities (28/62, 45.2\% vs. $5 / 10,50 \%)$.

Table 2 Patients with more than one isolate

\begin{tabular}{lllll}
\hline Patient ID & Age (years) & Sex & Isolates & Outcome (symptoms disappeared after 14 days) \\
\hline 29 & 35 & Female & Klebsiella pneumoniae Escherichia coli & Yes \\
46 & 30 & Male & Escherichia coli Unidentified GNR & No \\
136 & 39 & Male & Pseudomonas aeruginosa Unidentified GNR & No \\
271 & 31 & Male & Klebsiella pneumoniae Enterobacter aerogenes & NO \\
278 & 76 & Male & Klebsiella pneumoniae Citrobacter freundii & Yes \\
\hline
\end{tabular}




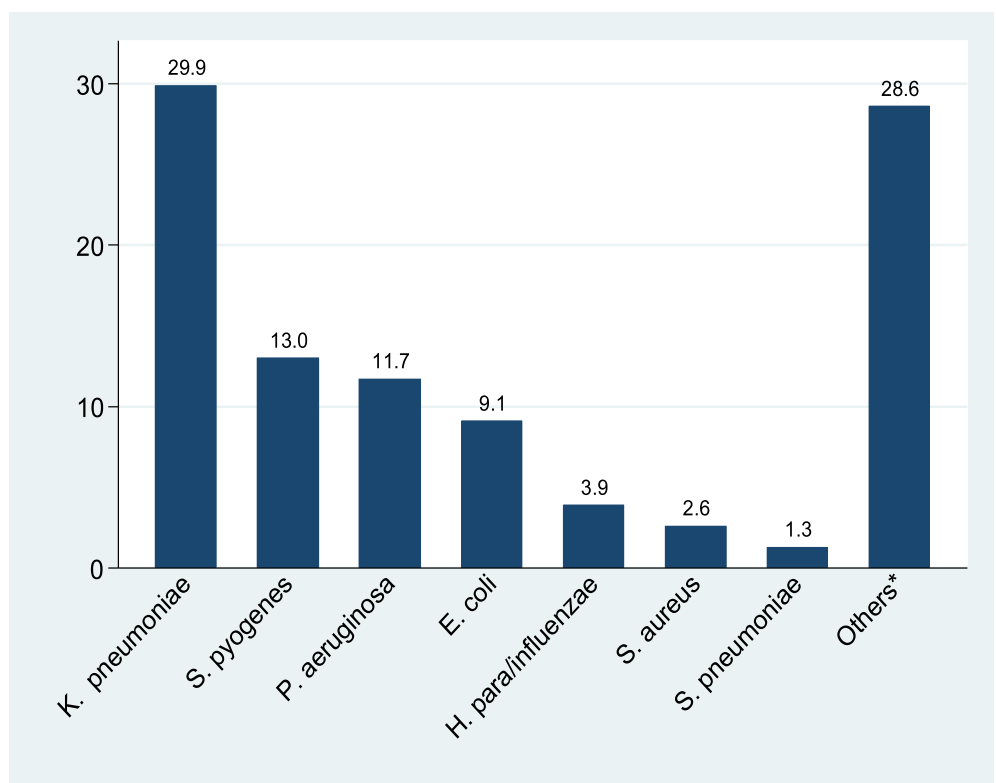

Fig. 2 Bacterial isolates from 72 patients with positive sputum culture

\section{Factors associated with symptoms disappearance after 14 days follow up}

Out of 72 patients with sputum culture positive, 45 (62.5\%) presented with no symptoms after 14 days compared to $218(77.6 \%)$ of those who were culture negative $(\mathrm{OR}=2$ 95\%CI; $1.25-3.30, p=0.010)$. Resistance to the second line antibiotic was associated with persistence of symptoms in the majority of cases. Further analysis revealed that, 14(82.3\%) of those infected with gram negative isolates susceptible to ceftriaxone had their symptoms disappeared compared to only $17(44.7 \%)$ of those infected by ceftriaxone non susceptible isolates $(p=0.009)$ (Table 5).

\section{Discussion}

In this hospital based cross sectional study, bacterial pathogens were isolated in $20.4 \%$ of the patients which is lower than the findings in others studies in Bangladesh 27.6\%
[23], South Ethiopia 40.0\% [24], Iran 44\% [25], Nicaragua $45.0 \%$ [26] and Nigeria 47.2\% [27]. The difference could be explained by the fact that in those studies, the majority of patients enrolled were older than patients in present study. The bacterial CAP is more likely in older age than in young age group [28]. The absence of bacterial isolates in the majority of the patients in this study could be attributed by antibiotics use before presentation to hospital [29] as evidenced by the fact that, sputa from patients with history of antibiotic use had low yield. However; other studies have observed that despite comprehensive diagnostic work-up, causes of CAP in adults may remain undetermined in $40-60 \%$ of individuals even in the best centers $[1,30]$. Other explanation could be that the etiology of CAP in this cohort could be viruses as observed in previous study that viruses might be confirmed as cause of CAP in $29 \%$ of adult patients [5].

Table 3 Resistance rates for bacterial pathogens from adult patients with community acquired pneumonia between August and December 2015 in Mwanza, Tanzania

\begin{tabular}{|c|c|c|c|c|c|c|c|c|c|c|c|c|}
\hline ISOLATE & AMP & $\mathrm{CIP}$ & $\mathrm{CN}$ & SXT & AMC & CRO & MEM & TET & $P$ & $E$ & VA & $\mathrm{DA}$ \\
\hline K. pneumoniae (23) & $100 \%)$ & $17.4 \%$ & $26.1 \%$ & $43.5 \%$ & $91.3 \%$ & $87.0 \%$ & $4.3 \%$ & NT & NA & NA & NA & NA \\
\hline E. coli (7) & $100 \%$ & $28.6 \%)$ & $14.3 \%$ & $71.4 \%$ & $85.7 \%$ & $85.7 \%$ & $0.0 \%$ & NT & NA & NA & NA & NA \\
\hline P. aureginosa (9) & $100 \%$ & $50 \%$ & $39 \%$ & $100 \%$ & $100 \%$ & $90.0 \%$ & $0.0 \%$ & NA & NA & NA & NA & NA \\
\hline${ }^{a}$ Others GNB (25) & $68.2 \%$ & $9.1 \%$ & $0.0 \%$ & $40.9 \%$ & $36.4 \%$ & $77.0 \%$ & $0.0 \%$ & NT & NA & NA & NA & NA \\
\hline Str. pyogenes (10) & NA & $10.0 \%$ & $20.0 \%$ & $100.0 \%$ & NA & NA & NA & $10.0 \%$ & $0.0 \%$ & $10.0 \%$ & $0.0 \%$ & 0 \\
\hline Str. pneumoniae (1) & NT & NT & NT & NT & NA & NT & NT & $0.0 \%$ & $0.0 \%$ & $100 \%$ & NT & NT \\
\hline S. aureus (2) & NA & 0 & 0 & 0 & NA & NA & NA & $100 \%$ & NT & $50 \%$ & $0.0 \%$ & $0.0 \%$ \\
\hline
\end{tabular}

NT Not done, NA not applicable, AMP Ampicillin, CIP Ciprofloxacin, CN Gentamicin, SXT Trimethoprim/Sulphamethoxazole, AMC Amoxicillin/clavulanate, CRO Ceftriaxone, MEM Meropenem, TET Tetracycline, E Erythromycin, VA Vancomycin and DA Clindamycin

${ }^{a}$ Citrobacter freundii, Enterobacter aerogenes, Klebsiella oxytoca, Moraxella spp., Proteus mirabilis, Serratia marcescens and un-identified Gram Negative Rods (GNR), Haemophilus influenzae/parainfluenzae 
Table 4 Factors associated with Sputum Culture Positive of 353 adult patients with pneumonia between August and December 2015 in Mwanza, Tanzania

\begin{tabular}{|c|c|c|c|c|}
\hline \multirow[t]{2}{*}{ Predictor } & \multicolumn{2}{|c|}{ Sputum Culture } & \multicolumn{2}{|l|}{ Univariate } \\
\hline & Positive n (\%) & Negative n (\%) & OR[95\%-Cl] & $\boldsymbol{P}$-value \\
\hline \multicolumn{5}{|l|}{ Sex } \\
\hline Male & $41(22.7)$ & $140(77.3)$ & 1.0 & \\
\hline Female & $31(18.0)$ & $141(82.0)$ & $0.8[0.4-1.3]$ & 0.282 \\
\hline Age (years) & $39(32.5-53)$ & $40(32-52)$ & $1.0[0.99-1.01]$ & 0.950 \\
\hline \multicolumn{5}{|c|}{ Ever smoked tobacco products } \\
\hline No & $52(20.0)$ & $208(80.0)$ & 1.0 & \\
\hline Yes & $20(21.5)$ & $73(78.5)$ & $1.1[0.6-1.9]$ & 0.757 \\
\hline \multicolumn{5}{|c|}{ Alcohol-containing beverage } \\
\hline No & $43(22.8)$ & $146(77.2)$ & 1.0 & \\
\hline Yes & $29(17.7)$ & $135(82.3)$ & $0.7[0.4-1.2]$ & 0.240 \\
\hline \multicolumn{5}{|c|}{ Co morbidities } \\
\hline No & $62(19.8)$ & $251(80.2)$ & 1.0 & \\
\hline Yes & $10(25.0)$ & $30(75.0)$ & $1.3[0.6-2.9]$ & 0.444 \\
\hline \multicolumn{5}{|c|}{ Hospitalization in past 2 weeks } \\
\hline No & $70(20.1)$ & $278(79.9)$ & 1.0 & \\
\hline Yes & $2(40.0)$ & $3(60.0)$ & $2.6[0.4-16.1]$ & 0.291 \\
\hline \multicolumn{5}{|c|}{ Antibiotics use in the past 7 days } \\
\hline No & $42(18.2)$ & $189(81.8)$ & 1.0 & \\
\hline Yes & $30(24.6)$ & $92(75.4)$ & $1.5[0.9-2.5]$ & 0.157 \\
\hline \multicolumn{5}{|c|}{ HIV infection status } \\
\hline Negative & $46(21.2)$ & $171(78.8)$ & & \\
\hline Positive & $26(19.1)$ & $110(80.9)$ & $0.87[0.51-1.5]$ & 0.637 \\
\hline \multicolumn{5}{|c|}{ Quality of sputum sample } \\
\hline Poor & $3(3.4)$ & 86 (96.6) & 1.0 & \\
\hline Good & $69(26.1)$ & $195(73.9)$ & $10.1[3.1-33.1]$ & $<0.001$ \\
\hline
\end{tabular}

As in previous studies high quality sputum had significantly more yield of pathogenic bacteria than poor quality sputum $[31,32]$. The findings emphasize the importance of proper instructions to the patients to ensure high quality sputum specimens are obtained for microbiological investigations.

Gram negative bacteria were commonly isolated in the present study. Previous studies in Africa and elsewhere have reported similar results indicating a shift of pathogens trends [24, 33]. In contrast to studies in USA and Europe, only one patient in the present study was infected with $S$. pneumoniae $[9,23,34,35]$. Selfmedication of antibiotics in the study setting could explain this because the majority of $S$. pneumoniae strains are susceptible to erythromycin and amoxicillin which are commonly self-administered antibiotics [36, 37]. In addition, geographical variations of bacterial CAP in adults can contribute to the observed differences [7].
Table 5 Factors associated with symptoms disappearance after 14 days follow up of 353 adults' patients with pneumonia between August and December 2015 in Mwanza, Tanzania

\begin{tabular}{|c|c|c|c|c|}
\hline \multirow[t]{2}{*}{ Predictor } & \multicolumn{2}{|c|}{ Symptoms disappeared } & \multicolumn{2}{|l|}{ Univariate } \\
\hline & YES, n (\%) & NO n (\%) & $\mathrm{OR}[95 \% \mathrm{Cl}]$ & $\boldsymbol{P}$-value \\
\hline \multicolumn{5}{|l|}{ Sex } \\
\hline Male & $134(74.0)$ & $47(26.0)$ & 1.0 & \\
\hline Female & $129(75.0)$ & $43(25.0)$ & $1.1[0.7-1.7]$ & 0.835 \\
\hline Age (years) & $40(31-53)$ & $42(35-51)$ & $1.0[0.9-1.0]$ & 0.527 \\
\hline \multicolumn{5}{|c|}{ Sputum culture positive } \\
\hline Yes & $45(62.5)$ & $27(37.5)$ & 1.0 & \\
\hline No & $218(77.6)$ & $63(22.4)$ & $2[1.25-3.30]$ & 0.010 \\
\hline \multicolumn{5}{|l|}{ Gram staining } \\
\hline Gram negative & $37(62.7)$ & $22(37.3)$ & 1.0 & \\
\hline Gram positive & $8(61.5)$ & $5(38.5)$ & $2[0.66-10]$ & 0.189 \\
\hline No organism & $218(77.6)$ & $63(22.4)$ & $2[1.1-3.3]$ & 0.018 \\
\hline \multicolumn{5}{|l|}{ Treatment given } \\
\hline First line & $232(87.5)$ & $33(12.4)$ & 1 & \\
\hline Second line & $31(64.6)$ & $57(35.4)$ & $0.25(0.12-0.55)$ & $<0.001$ \\
\hline
\end{tabular}

Second line treatment antibiotics resistance

$\begin{array}{lllll}\text { No } & 14(82.3) & 3(17.7) & 1.0 & \\ \text { Yes } & 17(44.7) & 21(55.82) & 0.17[0.03-0.79] & \mathbf{0 . 0 0 9} \\ \text { Co morbidities } & & & & \\ \text { No } & 234(74.8) & 79(25.2) & 1.0 & \\ \text { Yes } & 29(72.5) & 11(27.5) & 0.9[0.4-1.9] & \mathbf{0 . 7 5 8}\end{array}$

HIV infection status

\begin{tabular}{lllll} 
Negative & $79(74.5)$ & $27(25.5)$ & & \\
Positive & $101(74.3)$ & $35(25.7)$ & $1.0[0.6-1.8]$ & 0.963 \\
\hline
\end{tabular}

As far as antibiotics susceptibility patterns is concerned, the majority of the isolates in this study were highly sensitive to meropenem and ciprofloxacin. These findings are similar to other studies carried out in Estonia and Nigeria [38, 39]. Nevertheless, a significant proportion of isolates were resistant to ceftriaxone, amoxicillin-clavulanic and ampicillin. These antibiotics are widely used empirically to treat adults with CAP in our setting. The observed resistance rates to these antibiotics were higher than other studies elsewhere [23, 38]. The higher resistance could be due to irrational use of these antibiotics in our setting, as it was further observed that in these hospitals ceftriaxone, amoxicillinclavulanic acid and ampicillin were commonly used to any patient with cough and fever regardless of the duration symptoms. The observation is further supported by the fact that those patients with history on antibiotic use were significantly more likely to be infected with uncommon pathogens such as Pseudomonas spp., E coli, Citrobacter spp., Enterobacter spp., Proteus spp. and Serratia spp. These pathogens tend to be more resistant 
than common pathogens. There is high antibiotics selfmedication in Tanzania that might contribute to high rate of multidrug resistant gram-negative bacteria causing community acquired pneumonia [40-43]. Furthermore it should be noted that these patients were enrolled at regional and tertiary hospitals therefore have either visited lower facilities for treatment or community pharmacy for self-medication.

The high resistance rates to commonly used antibiotics is also supported by previous community studies in the city of Mwanza by Bahati et al [44] and Mshana et al [45] which identified a significant proportion of Escherichia coli, Klebsiella pneumoniae and other Enterobacteriaceae species (Enterobacter spp., Proteus mirabilis and Proteus vulgaris) being resistant to ceftriaxone, ampicillin, trimethoprim/sulfamethoxazole, amoxicillin/clavulanic and gentamicin. Recent review has shown that CAP due to multi-drug resistant is common and is associated with significant morbidity and mortality and it was emphasized that identification of these pathogens and patients at risk is very important in order to institute appropriate antibiotic treatment [46].

Positive sputum culture, gram stain with predominant gram negative bacteria and resistance to second line antibiotics were significantly associated with low rates of symptoms disappearance. Regarding gram staining and treatment outcome, findings of this study are similar to those reported by Liao X et al in Tianjian [47]. A study in Nigeria also observed that the resistance to ceftriaxone was associated with longer duration of hospital stay for hospitalized patients with CAP [38]. It should be noted patients who received second line treatment were more likely to have resistant pathogens because of previous antibiotic exposure.

Limitation of this study included: Failure to identify atypical bacteria because serological or molecular techniques were not available at the study setting. In addition, chest $-\mathrm{x}$-ray and blood culture were not performed. However clear criteria were used to enrol the patients with suspected community acquired pneumonia and sputum culture [48] has been found to be useful in the diagnosis of community acquired pneumonia with limited usefulness of blood culture in relation to yield and cost [49].

\section{Conclusion}

Gram negative bacteria are the commonest cause of CAP among adults in the city of Mwanza, north-western Tanzania. These isolates were significantly resistant to first and second line antibiotics commonly used in our setting. Resistance to commonly used antibiotics (cephalosporins) for empirical treatment of CAP in the region was associated with worse outcome in terms of symptoms disappearance. Based on these findings there is a need for an evidence based treatment guidelines for CAP in developing countries. In the absence of other advanced diagnostic techniques in developing countries and limited usefulness of blood culture, there is a need to emphasize sputa culture to guide antibiotic treatment for bacterial CAP in developing countries.

\section{Abbreviations}

ATCC: American type culture collection; BMC: Bugando Medical Centre; CAP: Community acquired pneumonia; CUHAS: Catholic University of Health and Allied Sciences; CLSI: Clinical Laboratory Standard Institute; CDC: Center for Disease control; COPD: Chronic Pulmonary Diseases; ESBL: Extended Spectrum beta-lactamases; MOPD: Medical outpatient Department; EMD: Emergence medicine department

\section{Acknowledgements}

We thank Mr. Vitus Silago for the diligent technical laboratory assistance he provided during the study period. We also thank staff from Sekou Toure and Bugando Medical Centre for their cooperation during data collection.

\section{Authors' contributions}

PK, FK and SEM conceived, designed and executed the study; PK collected the data and samples; PK, NMS and SEM performed laboratory analysis; PK wrote the manuscript which was critically reviewed by all authors. All authors have read and approved the final draft of the manuscript.

\section{Funding}

This study was supported by a grant from Ministry of health to PK and from CUHAS to SEM.

\section{Availability of data and materials \\ The datasets used and/or analyzed during the current study available from the corresponding author on reasonable request.}

\section{Ethics approval and consent to participate}

Ethical clearance (CREC/092/2015) was sought from the Joint CUHAS/BMC Research Ethics and scientific review committee. Permission to conduct the study was obtained from the BMC and Sekou Toure Regional Hospital authorities. An informed consent was obtained from each participant after explaining the study aims. For literate participants, the consent information was provided, followed by providing a copy of the consent form for each participant to sign to signify his/her consent. For non-literate participants, the consent information was read in full and participant required to thumb print on the consent form to signify his/her acceptance to participate in the study.

Consent for publication

Not applicable.

\section{Competing interests}

The authors declare that they have no competing interests.

\section{Author details}

'Department of Internal Medicine, Weill Bugando School of Medicine, Mwanza, Tanzania. ${ }^{2}$ National Health Laboratory Quality Assurance and Training Centre, Dar es Salaam, Tanzania. ${ }^{3}$ Department of Microbiology/ Immunology, Weill Bugando School of Medicine, Mwanza, Tanzania.

Received: 28 November 2019 Accepted: 7 June 2020

Published online: 05 August 2020

\section{References}

1. Society BT. Guidelines for the Management of Community Acquired Pneumonia in Adults Update 2009 A Quick Reference Guide. In: thorax. thorax; 2009.

2. Thomas CP, Ryan M, Chapman JD, Stason WB, Tompkins CP, Suaya JA, Polsky D, Mannino DM, Shepard DS. Incidence and cost of pneumonia in Medicare beneficiaries. CHEST J. 2012;142(4):973-81.

3. Ruuskanen O, Lahti E, Jennings LC, Murdoch DR. Viral pneumonia. Lancet. 2011;377(9773):1264-75. 
4. File TM. Community-acquired pneumonia. Lancet. 2003;362(9400):1991-2001.

5. Jennings LC, Anderson TP, Beynon KA, Chua A, Laing RT, Werno AM, Young SA, Chambers ST, Murdoch DR. Incidence and characteristics of viral community-acquired pneumonia in adults. Thorax. 2008;63(1):42-8.

6. Bartlett JG, Mundy LM. Community-acquired pneumonia. N Engl J Med. 1995;333(24):1618-24.

7. Niederman MS, Luna CM. Community-acquired pneumonia guidelines: a global perspective. In: Seminars in respiratory and critical care medicine, vol. 2012; 2012. p. 298

8. Mandell LA, Wunderink RG, Anzueto A, Bartlett JG, Campbell GD, Dean NC, Dowell SF, File TM, Musher DM, Niederman MS. Infectious Diseases Society of America/American Thoracic Society consensus guidelines on the management of community-acquired pneumonia in adults. Clin Infect Dis. 2007;44(Supplement 2):S27-72.

9. Shah BA, Singh G, Naik MA, Dhobi GN. Bacteriological and clinical profile of community acquired pneumonia in hospitalized patients. Lung India. 2010; 27(2):54.

10. Lode HM. Managing community-acquired pneumonia: a European perspective. Respir Med. 2007:101(9):1864-73.

11. Rubach MP, Maro VP, Bartlett JA, Crump JA. Etiologies of illness among patients meeting integrated Management of Adolescent and Adult Illness District Clinician Manual Criteria for severe infections in northern Tanzania: implications for empiric antimicrobial therapy. Am J Trop Med Hyg. 2015; 92(2):454-62.

12. Cochran WG. Sampling techniques: Wiley; 2007.

13. Scott J, Hall A, Muyodi C, Lowe B, Ross M, Chohan B, Mandaliya K, Getambu E, Gleeson F, Drobniewski F. Aetiology, outcome, and risk factors for mortality among adults with acute pneumonia in Kenya. Lancet. 2000; 355(9211):1225-30.

14. Glynn M, Drake WM, Hutchison R. Hutchison's clinical methods, an integrated approach to clinical practice with STUDENT CONSULT online access, 23: Hutchison's clinical methods: Elsevier Health Sciences; 2012

15. Lyamuya EF, Aboud S, Urassa WK, Sufi J, Mbwana J, Ndugulile F, Massambu C. Evaluation of simple rapid HIV assays and development of national rapid HIV test algorithms in Dar Es Salaam, Tanzania. BMC Infect Dis. 2009;9(1):19.

16. Winn WC, Koneman EW. Koneman's color atlas and textbook of diagnostic microbiology: Lippincott Williams \& wilkins; 2006.

17. WHO. Manual of Basic Techniques for a Health Laboratory. 2nd ed. Geneva; 2003.

18. Laboratory PH. Standard manual for Laboratory technicians on sputum smear microscopy. Thimphu: Ministry of Health; 2011.

19. Bartlett JG, Dowell SF, Mandell LA, File TM Jr, Musher DM, Fine MJ. Practice guidelines for the management of community-acquired pneumonia in adults. Clin Infect Dis. 2000;31(2):347-82.

20. Winn WC. Koneman's color atlas and textbook of diagnostic microbiology: Lippincott Williams \& wilkins; 2006.

21. Mshana SE, Kamugisha E, Mirambo M, Chakraborty T, Lyamuya EF. Prevalence of multiresistant gram-negative organisms in a tertiary hospital in Mwanza, Tanzania. BMC Res Notes. 2009;2(1):49.

22. Jorgensen JH, Turnidge JD. Susceptibility test methods: dilution and disk diffusion methods. In: Manual of Clinical Microbiology, Eleventh Edition: American Society of Microbiology; 2015. p. 1253-73.

23. Akter S, Shumsuzzaman S, Jahan F. Community acquired bacterial pneumonia: aetiology, laboratory detection and antibiotic susceptibility pattern. Malays J Pathol. 2014;36(2):97-103.

24. Regasa B. Drug Resistance Patterns of Bacterial Pathogens from Adult Patients with Pneumonia in Arba Minch Hospital, South Ethiopia. Glob J Med Res. 2014;14(5)

25. Hashemi SH, Soozanchi G, Jamal-Omidi S, Yousefi-Mashouf R, Mamani M, Seif-Rabiei M-A. Bacterial aetiology and antimicrobial resistance of community-acquired pneumonia in the elderly and younger adults. Trop Dr. 2010;40(2):89-91.

26. Matute A, Brouwer W, Hak E, Delgado E, Alonso E, Hoepelman I. Aetiology and resistance patterns of community-acquired pneumonia in Leon, Nicaragua. Int J Antimicrob Agents. 2006;28(5):423-7.

27. Egbagbe $E$, Mordi R. Aetiology of lower respiratory tract infection in Benin City, Nigeria; 2007

28. Ruiz M, Ewig S, Marcos MA, Martinez JA, Arancibia F, Mensa J, Torres A. Etiology of community-acquired pneumonia: impact of age, comorbidity, and severity. Am J Respir Crit Care Med. 1999:160(2):397-405.
29. Kang JY, Kim SJ. Reasons for low bacterial yields from quantitative cultures of Bronchoalveolar lavage fluid. Korean J Intern Med. 2012;27(2):149.

30. van Gageldonk-Lafeber A, Wever P, van der Lubben I, de Jager C, Meijer A, de Vries M, Elberse K, van der Sande M, van der Hoek W. The aetiology of community-acquired pneumonia and implications for patient management. Neth J Med. 2013;71(8):418-25.

31. Campbell S, Forbes BA. The clinical microbiology laboratory in the diagnosis of lower respiratory tract infections. J Clin Microbiol. 2011;49(9 Supplement): S30-3.

32. Moncayo O, Nieto M, Reid P, Lipka A, Hamilton T, Laurenson I, Simpson A. Improving the use of sputum cultures in lower respiratory tract infection. Am J Respir Crit Care Med. 2009;179:A2586.

33. Arancibia F, Bauer TT, Ewig S, Mensa J, Gonzalez J, Niederman MS, Torres A. Community-acquired pneumonia due to gram-negative bacteria and Pseudomonas aeruginosa: incidence, risk, and prognosis. Arch Intern Med. 2002;162(16):1849-58.

34. Holter JC, Müller F, Bjørang O, Samdal HH, Marthinsen JB, Jenum PA, Ueland T, Frøland SS, Aukrust P, Husebye E. Etiology of community-acquired pneumonia and diagnostic yields of microbiological methods: a 3-year prospective study in Norway. BMC Infect Dis. 2015;15(1):64.

35. Spoorenberg SM, Bos WJ, Heijligenberg R, Voorn PG, Grutters JC, Rijkers GT, van de Garde EM. Microbial aetiology, outcomes, and costs of hospitalisation for community-acquired pneumonia; an observational analysis. BMC Infect Dis. 2014;14(1):335.

36. Ndosa A, Kidenya BR, Mushi MF, Mirambo MM, Hokororo A, Mshana SE. Factors associated with colonization of Streptococcus pneumoniae among under-fives attending clinic in Mwanza City, Tanzania. Tanzan J Health Res. 2015;17(1).

37. Moyo SJ, Steinbakk M, Aboud S, Mkopi N, Kasubi M, Blomberg B, Manji K, Lyamuya EF, Maselle SY, Langeland N. Penicillin resistance and serotype distribution of Streptococcus pneumoniae in nasopharyngeal carrier children under 5 years of age in Dar Es Salaam, Tanzania. J Med Microbiol. 2012;61(7):952-9.

38. Iroezindu MO, Chima El, Isiguzo GC, Mbata GC, Onyedum CC, Onyedibe KI, Okoli LE. Sputum bacteriology and antibiotic sensitivity patterns of community-acquired pneumonia in hospitalized adult patients in Nigeria: a 5year multicentre retrospective study. Scand J Infect Dis. 2014;46(12):875-87.

39. Leesik H, Ani U, Juhani A, Altraja A. Microbial pathogens of adult community-acquired pneumonia in southern Estonia. Medicina (Kaunas) 2006:42(5):384-94.

40. Kajeguka DC, Moses E. Self-medication practices and predictors for selfmedication with antibiotics and antimalarials among community in Mbeya City, Tanzania. Tanzan J Health Res. 2017;19(4).

41. Gwimile JJ, Shekalaghe SA, Kapanda GN, Kisanga ER. Antibiotic prescribing practice in management of cough and/or diarrhoea in Moshi Municipality, Northern Tanzania: cross-sectional descriptive study. Pan African Medical Journal. 2012;12(1).

42. Horumpende PG, Said SH, Mazuguni FS, Antony ML, Kumburu HH, Sonda TB, Mwanziva CE, Mshana SE, Mmbaga BT, Kajeguka DC. Prevalence, determinants and knowledge of antibacterial self-medication: A cross sectional study in North-eastern Tanzania. PLoS One. 2018;13(10).

43. Horumpende PG, Sonda TB, van Zwetselaar M, Antony ML, Tenu FF, Mwanziva CE, Shao ER, Mshana SE, Mmbaga BT, Chilongola JO. Prescription and non-prescription antibiotic dispensing practices in part I and part II pharmacies in Moshi Municipality, Kilimanjaro Region in Tanzania: A simulated clients approach. PLoS One. 2018;13(11).

44. Msaki BP, Mshana SE, Hokororo A, Mazigo HD, Morona D. Prevalence and predictors of urinary tract infection and severe malaria among febrile children attending Makongoro health Centre in Mwanza city, North-Western Tanzania. Arch Public Health. 2012;70(1):1-8

45. Mshana SE, Falgenhauer L, Mirambo MM, Mushi MF, Moremi N, Julius R, Seni J, Imirzalioglu C, Matee M, Chakraborty T. Predictors of bl a CTX-M-15 in varieties of Escherichia coli genotypes from humans in community settings in Mwanza, Tanzania. BMC Infect Dis. 2016;16(1):1.

46. Cillóniz C, Dominedò C, Torres A. Multidrug resistant gram-negative bacteria in community-acquired pneumonia. Crit Care. 2019;23(1):79.

47. Liao X, Ran Y, Bian S, Wang C, Xu L. Value of optimization of bedside gram staining of sputum smear in the early diagnosis and treatment of ventilatorassociated pneumonia. Zhonghua Wei Zhong Bing Ji Jiu Yi Xue. 2014; 26(12):879-83. 
48. García-Vázquez E, Marcos MA, Mensa J, de Roux A, Puig J, Font C, Francisco $\mathrm{G}$, Torres A. Assessment of the usefulness of sputum culture for diagnosis of community-acquired pneumonia using the PORT predictive scoring system. Arch Intern Med. 2004:164(16):1807-11.

49. Chalasani NP, Valdecanas MAL, Gopal AK, McGowan JE Jr, Jurado RL. Clinical utility of blood cultures in adult patients with community-acquired

pneumonia without defined underlying risks. Chest. 1995;108(4):932-6.

\section{Publisher's Note}

Springer Nature remains neutral with regard to jurisdictional claims in published maps and institutional affiliations.

Ready to submit your research? Choose BMC and benefit from:

- fast, convenient online submission

- thorough peer review by experienced researchers in your field

- rapid publication on acceptance

- support for research data, including large and complex data types

- gold Open Access which fosters wider collaboration and increased citations

- maximum visibility for your research: over $100 \mathrm{M}$ website views per year

At BMC, research is always in progress.

Learn more biomedcentral.com/submissions 